\title{
Ultrasound approach to the Wilson's disease
}

\author{
Petar Avramovski ${ }^{1 *}$, Maja Avramovska ${ }^{2}$, Kosta Sotiroski ${ }^{3}$ Pece Nikoloski $^{3}$ and Emilija Sikole ${ }^{4}$ \\ ${ }^{1}$ Clinical Hospital “D-r TrifunPanovski”, Department of internal medicine, Partizanska bb. 7000 Bitola, Macedonia, Professor of High Medical School and Faculty \\ of Veterinary Medicine, St. Clement of Ohrid University- Bitola, Partizanska bb. 7000 Bitola, Macedonia \\ ${ }^{2}$ University Clinic of Obstetrics and Gynecology, Specializing at University “SS. Cyril and Methodius”, Vodnjanska 17, 1000, Skopje, Macedonia \\ ${ }^{3}$ Faculty of economics - Prilep, St. Clement of Ohrid University- Bitola, Professor of Faculty of Economics and statistics, Marksovab.b. 7500 Prilep, Macedonia \\ ${ }^{4}$ Institute of Preclinical and Clinical Pharmacology with Toxicology, University “SS. Cyril and Methodius”, Vodnjanska 17, 1000, Skopje, Macedonia
}

\section{Introduction}

Wilson disease $(\mathrm{WD})$ is an autosomal recessive disorder of copper transport which map to chromosome 13q14.3, characterized by the toxic accumulation of copper in a number of organs, particularly the liver and brain $[1,2]$. Named after the Samuel Kinnear Wilson who identified it in 1912, WD disease is also known as "hepatolenticular degeneration".

Wilson disease is often fatal if not recognized and treated when symptomatic. The main hepatic dysfunctions are present and may manifest as acute hepatitis, chronic active hepatitis, cirrhosis and fulminant hepatic failure $[3,4]$. Most patients with cirrhosis present neuropsychiatric and systemic manifestation: ataxia, difficulty speaking, personality changes, dystonia, spasticity, grand mal seizures, cognitive disorders, arthropathy in the spine and appendicular joints, osteohondritis, intravascular hemolysis, hematuria and Kayser-Fleisher rings $[4,5]$. It is not clear whether neurological signs and symptoms occur early in the course of the disease when liver involvement is mild (i.e., pre-cirrhotic) or whether they appear after the development of liver damage and cirrhosis. It has been suggested that neuropsychiatric symptoms in WD develop secondary to liver involvement [6].

Wilson disease - an inborn copper metabolism defect, is traditionally diagnosed on the basis of clinical features, positive family history, biochemical parameters, the presence of Kayser-Fleischer rings on slit lamp eye examination, and neurologic abnormalities $[7,8]$. In adition to standard laboratory procedures (alanine aminotransferase, aspartataminotransferase, the cooper level in serum, cooper excretion passed into urine and a caeruloplasmin concentration test) the liver biopsy is a gold standard to measure the amount of cooper (hepatic concentration) in the liver.

Imaging equipment such as ultrasonography, doppler ultrasonography, magnetic resonant imagery (MRI) or computised tomography (CT) is used to examine a specific area of the brain known as the basal ganglia and liver parenchyma. Ultrasound and Doppler examination of the liver in Wilson disease does not differ from the standard liver examinations that are made in other diffuse parenchymal lesion of the liver such as hepatitis, steatofibrosis and cirrhosis. Even the minimal alteration in the liver arterial and vein blood flow measured by Doppler ultrasound, as well as changes in the brightness and echo texture of liver parenchyma can be brought into association with the onset of the WD.

\section{Ultrasound in WD}

The WD liver parenchyma echo pattern was of increased echogenicity with numerous roundish foci of decrease echogenicity resembling metastatic liver disease, like focal nodular hyperplasia on hyperechoic liver echotexture (Figure 1) because its predominancy of fatty steatotic changes and fibrosis [3]. For the best imaging in distinguishing of focal nodes from liver parenchymal fatty, B-mode, optimization of brightness, contrast, probe frequency, focusing, dynamic range, time gain compensation and gain is necessary [9].

Several studies found the similar liver parenchymal changes by ultrasound in WD [10]. Normal size of the lobuscaudatus and parenchymal athrophy (liver antero-posterior diameter in mean medioclavicular line $<10 \mathrm{~cm}$ ) was evident. The specific features of ultrasound imaging of the liver in WD include multiple nodular lesion, presence of hiperechogenic perihepatic fat layer and normal sized of

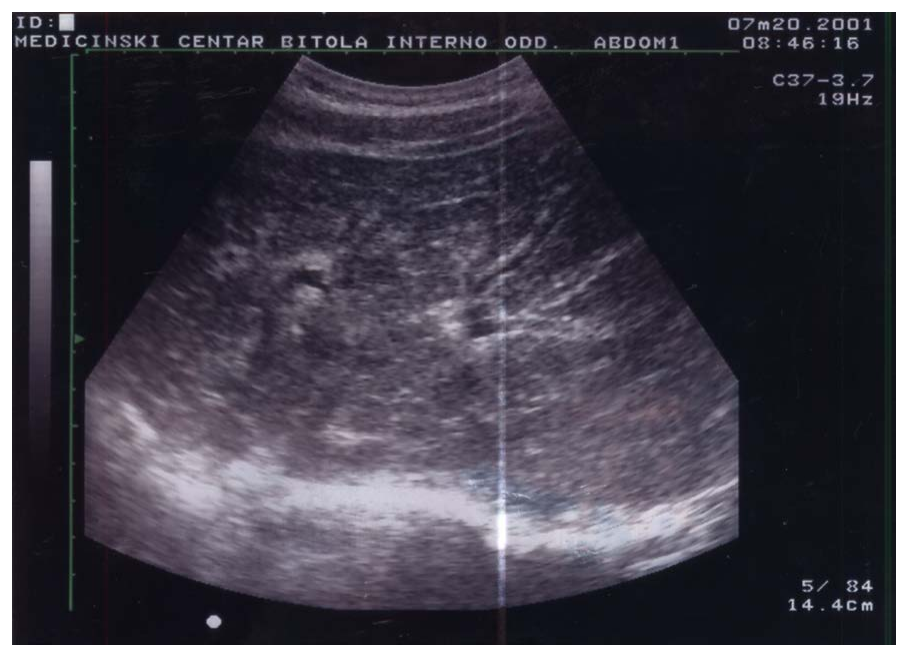

Figure 1. Wilson disease, B-mode ultrasound liver manifestation.

Correspondence to: PetarAvramovski, Clinical Hospital "D-r TrifunPanovski", Department of internal medicine, Partizanska bb. 7000 Bitola, Macedonia, Professor of High Medical School and Faculty of Veterinary Medicine, St. Clement of Ohrid University- Bitola, Partizanska bb. 7000 Bitola, Macedonia, E-mail: avramovski@gmail.com

Received: January 08, 2017; Accepted: January 16, 2017; Published: January 19,2017 
caudate lobe which is opposite of other cirrhotic ultrasound findings.

Doppler ultrasonography of the hepatic vasculature is an integral part of evaluating precirrhotic, cirrhotic and WD patients. Early diagnosis of WD and alteration of blood flow speed and pattern may help prevent the associated detrimental effects, including variceal bleeding, hepatic encephalopathy, and portal vein thrombosis [11].

In patients with WD because rise of the parenchymal density and rich arterio-portal shunting, the normal portal vein gentle undulated waveform is replaced by high pulsatility waveform (Figure2). We detected and measured in early stage of WD normal blood flow pattern (gentle undulated, Figure 3), but with low speed of flow volume $\left(\mathrm{V}_{\text {mean }}\right.$ $=13 \mathrm{~cm} / \mathrm{s}$ ).

Increased pulsatility in advanced stage of WD, defined as an increase in the pulsatility index, occurs due to the transmission of pressure across the hepatic sinusoids during the end diastole (Figure 3) $[12]$.

In early stage of WD before liver cirrhosis has not appeared yet, we measured reference value of resistive index $(\mathrm{RI}=0.578)$ and pulsatility index $(\mathrm{PI}=0.96)$ of hepatic artery leftbranch (Figure 4$)$. The RI (RI = peak systolic velocity - end diastolic velocity)/peak systolic velocity) is the commonest Doppler parameter used for hepatic arterial evaluation. The usual range in normal individuals is between 0.55 and 0.65 .

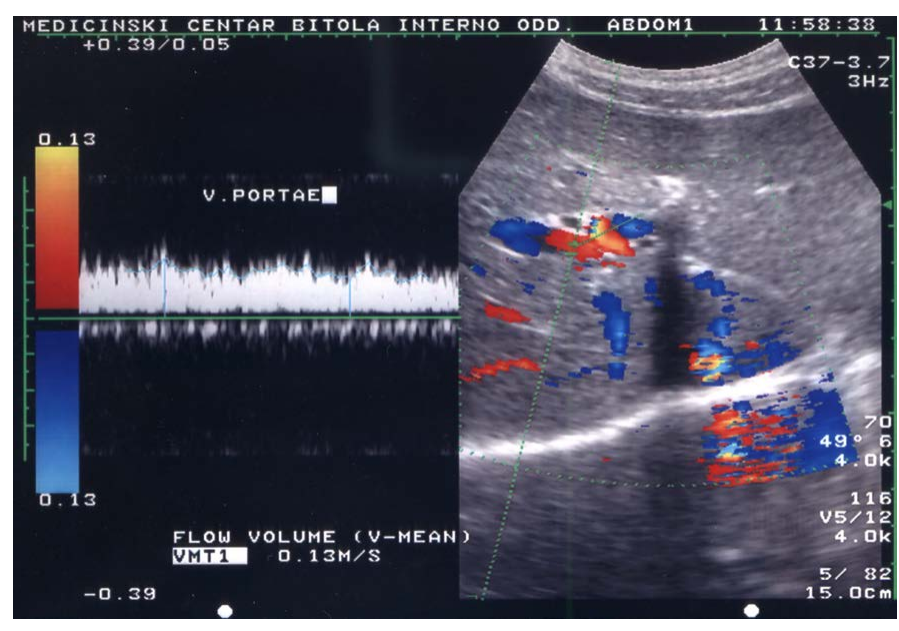

Figure 2. High pulsatility of portal vein flow in wilson disease.

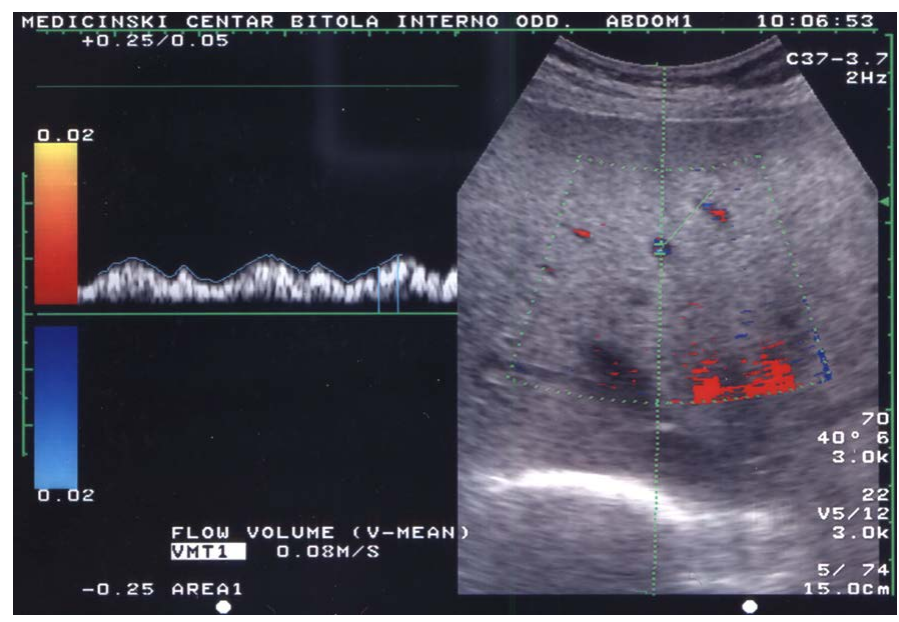

Figure 3. Color doppler angiodinography of portal vein in early stage of wilson disease.

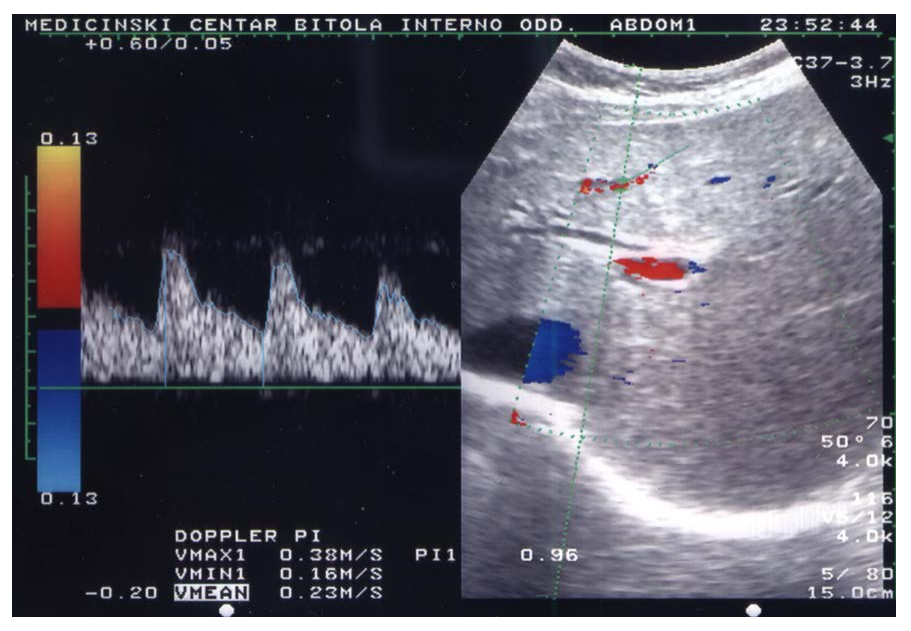

Figure 4. Color doppler angiodinography of hepatic artery in WD.

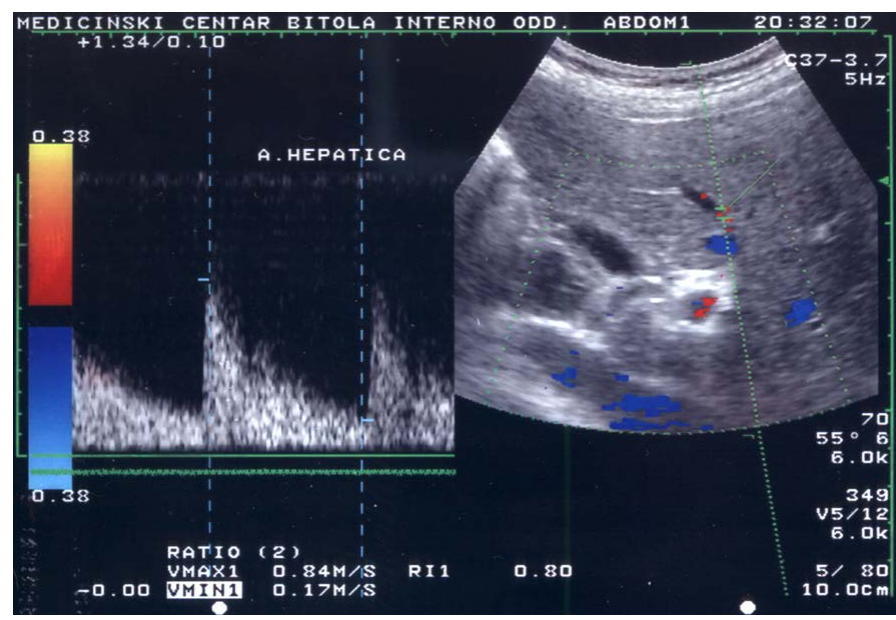

Figure 5. Elevated RI of hepatic artery in advanced WD.

Compared with controls, the patients with WD, and alcoholicpatients without liver disease, the chronic alcoholic patientswith cirrhosis had an elevated hepatic arterial RI, as didpatients with cirrhosis of viral etiology indicatingthat the progression of liver damage from WD to cirrhosisimpairs the arterial responsiveness because offibrosis [13].

The RI significantly increased in patients with alcoholic, WD and viral-related cirrhosis $(0.74 \pm 0.04)$ because of increased liver vascular resistivity caused by elevated parenchymal density during fibrosis [14]. The figure 5 present doppler flow in hepatic artery with significant elevation of RI to 0.80 , with hipoechoic roundish and focal increased echogenicity with numerous roundish foci of decrease echogenicity resembling metastatic liver disease or focal nodular hyperplasia during cirrhosis in VD.

In this way, we present you, in which way color Doppler and B-mode ultrasonography can significantly contribute to the early detection of parenchymal lesions and vascular blood flow in the livers parenchyma with diffuse parenchymal lesions such as Wilson's disease.

\section{References}

1. Petrukhin K, Fischer SG, Pirastu M, Tanzi RE, Chernov I, et al. (1993) Mapping, cloning and genetic characterization of the region containing the Wilson disease gene. Nat Genet 5: 338-343.[Crossref]

2. Tanzi RE, Petrukhin K, Chernov I, Pellequer JL, Wasco W, et al. (1993) The Wilson 
disease gene is a cooper transporting ATPase with homology to the Menkes disease gene. Nat Genet 5: 344-350.[Crossref]

3. Vogel W, Kathrein H, Dietze O, Judmaier G (1988) Sonography of the liver in Wilson's disease. Sonographic studies of the liver in Wilson's disease - significance for assessing prognosis? Ultraschall Med 9: 270-273.[Crossref]

4. Dusek P, Roos PM, Litwin T, Schneider SA, Flaten TP, et al. (2015) The neurotoxicity of iron, copper and manganese in Parkinson's and Wilson's diseases. J Trace Elem Med Biol 31: 193-203.[Crossref]

5. Merle U, Schaefer M, Ferenci P, Stremmel W (2007) Clinical presentation, diagnosis and long-term outcome of Wilson's disease: a cohort study. Gut 56: 115-120.[Crossref]

6. Harris S, Naina HV, Siddique S (2007) Wilson's disease. Lancet 369: 902-903.

7. Das SK, Ray K (2006) Wilson's disease: an update. Nat Clin Pract Neurol 2: 482-493. [Crossref]

8. Loudianos G, Gitlin JD (2000) Wilson's disease. Sem Liver Dis29: 353-364.
9. Avramovski P (2009) Value of ultrasound machine settings optimization for better diagnosis of focal liver lesions. OA Maced J of Med Science 2: 149-152.

10. Akhan O, Akpinar E, Karcaaltincaba M, Haliloglu M, Akata D, et al. (2009) Imaging findings of liver involment of Wilson's disease. Eur J Radiol 69: 147-155.[Crossref]

11. Iranpour P, Lall C, Houshyar R, Helmy M, Yang A, et al. (2016) Altered doppler flow I cirrhosis patients: an overview. Ultrasonography 35: 3-12.[Crossref]

12. McNaughton DA, Abu-Yousef MM (2011) Doppler US of the liver made simple. Radiographics 31: 161-188.[Crossref]

13. Colli A, Cocciolo M, Mumoli N, Cattalini N, Fraquelli M, et al. (1998) Hepatic artery resistance in alcoholic liver disease. Hepatology 28: 1182-1186.[Crossref]

14. Han SS, Rice S, Pedersen H, Stewart C, Reynolds TB, et al. (1996) Ultrasonographic determination of the hepatic artery resistive index can accurately diagnose acute alcoholic hepatitis. Hepatology 24: 146-151.

Copyright: (C2017 Avramovski P. This is an open-access article distributed under the terms of the Creative Commons Attribution License, which permits unrestricted use, distribution, and reproduction in any medium, provided the original author and source are credited. 